\title{
Molecular evidence of Plasmodium vivax infection in Duffy negative symptomatic individuals from Dschang, West Cameroon
}

\author{
Gianluca Russo ${ }^{1 *}+\left(\mathbb{0}\right.$, Giovanni Faggioni ${ }^{2+}$, Giacomo Maria Paganotti ${ }^{3}$, Ghyslaine Bruna Djeunang Dongho ${ }^{1}$, \\ Alice Pomponi ${ }^{2}$, Riccardo De Santis², Gianpiero Tebano ${ }^{1}$, Mpoame Mbida ${ }^{4}$, Martin Sanou Sobze ${ }^{4}$, \\ Vincenzo Vullo ${ }^{1}$, Giovanni Rezza ${ }^{5}$ and Florigio Romano Lista ${ }^{2}$
}

\begin{abstract}
Background: Plasmodium vivax infection is known to be rare in West/Central Africa, the most accepted explanation being the lack of expression of erythroid Duffy antigen in the local human populations. Duffy negativity prevents the parasite to exploit the entry mechanism on the red blood cell surface. However, there are a growing number of reported vivax infections in Duffy-negative individuals. Data on P. vivax circulation in Cameroon are limited. The aim of the study was to evaluate the P. vivax presence, and its association with the Duffy genotype in West Cameroon.

Results: Overall, 484 blood samples were collected consecutively from febrile outpatients attending the Dschang's Hospital (West Cameroon) during a 3-months period. Plasmodium vivax infection was detected by PCR in $5.6 \%$ $(n=27 / 484)$ of the cases, representing $38.6 \%(n=27 / 70)$ of all Plasmodium infections detected. All P. vivax infected individuals showed a Duffy-negative genotype, and the frequency of Duffy-positive individuals in the whole tested population was $1.7 \%$.
\end{abstract}

Conclusions: The results of this study confirm the circulation of P. vivax in Cameroon, as well as that the lack of expression of Duffy-antigen does not confer full protection against vivax malaria acquisition.

Keywords: Cameroon, Duffy antigen genotype, Malaria, Plasmodium vivax

\section{Background}

The World Health Organization (WHO) has estimated that a total of 214 million new cases of malaria occurred globally in 2014, with 438,000 related deaths, mostly related to Plasmodium falciparum and located in subSaharan Africa [1]. Plasmodium vivax is responsible of $8 \%$ of estimated malaria cases worldwide (about $50 \%$ when excluding sub-Saharan Africa), with three countries (Ethiopia, India and Pakistan) accounting for $80 \%$ of the cases [1]. Plasmodium vivax has a wider geographic distribution than P. falciparum, which is mostly prevalent in sub-Saharan Africa [1]. Possible explanations for

\footnotetext{
*Correspondence: gianluca.russo@uniroma1.it

${ }^{\dagger}$ Gianluca Russo and Giovanni Faggioni contributed equally to this work

${ }^{1}$ Department of Public Health and Infectious Diseases, Sapienza

University of Rome, Piazzale Aldo Moro, 00185 Rome, Italy

Full list of author information is available at the end of the article
}

this could be that $P$. vivax is able to develop at lower temperatures in the vector $[2,3]$, and may survive for long periods as hypnozoite (dormant liver stage) representing a possible reservoir of the infection and a major obstacle toward vivax malaria eradication [4-6].

For a long time, scientists and decision makers have neglected malaria due to $P$. vivax because it was considered as "benign" malaria when compared with the "malignant" form caused by P. falciparum [2]. Clinical manifestations of $P$. vivax infection are generally less severe than those related to $P$. falciparum infection, possibly because $P$. vivax infects mainly young red cells (reticulocytes), which are numerically limited (being $<2.5 \%$ of circulating red blood cells) and appear to be less prone to cytoadherence or sequestration in microcirculation $[2,7,8]$. Nevertheless there are still remarkably large 
knowledge gaps on the pathophysiology of vivax malaria [7-9].

The human Duffy antigen receptor is the only wellknown pathway used by $P$. vivax for erythrocyte invasion, through the interaction with the $P$. vivax Duffy binding protein (PvDBP) [10]. The Duffy antigen, also called Duffy Antigen Receptor for Chemokines (DARC), is a multimeric membrane protein organized into 7 transmembrane domains that is present in erythrocytes, endothelial cells (bone marrow, lung, kidney, adrenal gland, thyroid, spleen, colon), and epithelial cells (kidney collecting ducts, type-I alveolar lung cells, Purkinje cells of the cerebellum) [11]. The expression of the Duffy antigen on erythrocytes is linked to a single nucleotide polymorphism (SNP) $(-33 \mathrm{~T}>\mathrm{C})$ in the erythroid-specific promoter region (GATA box) of the DARC gene on chromosome 1 [12]. In carriers of the homozygous variant $(-33 C C)$ the Duffy antigen on the erythrocytes is absent (Duffy-negative phenotype), while in heterozygous carriers $(-33 T C)$ its expression is reduced $[12,13]$. The Duffy-negative phenotype reaches frequency of 95-100\% in West and Central African populations (and their descendants) and is extremely rare outside Africa [14], possibly explaining the low circulation of $P$. vivax in these geographical areas [1]. However, there is a growing number of reported cases of $P$. vivax infection in individuals with Duffy-negative erythroid phenotype, leading to hypothesize the existence of an alternative pathway for $P$. vivax erythrocyte invasion $[12,13,15]$.

In Cameroon, a country of the Central Africa subregion, $P$. falciparum is broadly considered responsible of up to $100 \%$ of malaria cases [1], and the vast majority (95-99\%) of the population has a Duffy-negative erythroid phenotype [14]. Very recently $P$. vivax infections have been reported in Cameroon among symptomatic $[16,17]$ and asymptomatic [18] Duffy-negative individuals from different regions (South, South-West, Littoral, East) in the southern part of the country. The primary objective of the present study was to evaluate the $P$. vivax circulation among febrile outpatients seeking medical care in Dschang, West region of Cameroon. A second objective was to explore the Duffy antigen genotype frequency among the study population.

\section{Methods}

\section{Study area and sample collection}

The study was carried out in Dschang, chief town of the Menoua Division, West region of Cameroon. The city of Dschang $\left(5^{\circ} 27^{\prime} \mathrm{N} ; 10^{\circ} 04^{\prime} \mathrm{E}\right)$, which is located at an altitude of 1400 masl, has an average annual temperature of $20.5 \pm 6{ }^{\circ} \mathrm{C}$, with February being the hottest month. Four seasons can be distinguished as follows: the main dry season (November to mid-March), the short rainy season (mid-March to May), the short dry season (June to July) and the main rainy season (August to October) [19]. According to local health authorities, the 2012 estimated district's population was of 218,006 inhabitants (17\% under-5 years old children), with the vast majority belonging to Bamiléké, a Bantu-related ethnic group. The local economy is mainly based on agriculture, livestock and trade. The presence of non-African people in Dschang is very limited, and foreign tourism is almost absent.

Samples were collected consecutively from febrile outpatients (all native Cameroonian) attending the District Hospital of Dschang, West Cameroon, during a 3-months period (December to February). Demographic and essential clinical data were collected from each patient. After venepuncture, an aliquot of $100 \mu \mathrm{l}$ of whole venous blood was spotted on filter paper (Whatman, UK), air-dried at room temperature, and then stored in locked bags at $+4{ }^{\circ} \mathrm{C}$.

\section{Nucleic acid extraction, analysis and sequencing reactions}

Human/parasite DNA was extracted by automated method using Maxwell ${ }^{\circledR} 16$ instrument (Promega, Madison, WI, USA) from the dried blood spots (DBS) collected. The presence of nucleic acids or PCR inhibitors in the extracted DBS was determined by amplification of a human house-keeping gene (acid phosphatase 1) [20]. The PCR analysis of the four mains species of Plasmodium (P. falciparum, P. vivax, Plasmodium ovale, Plasmodium malariae) was performed by a nestedPCR of specific $18 \mathrm{~S}$ rRNA gene fragments as previously described [21]. Four positive control DNA for all Plasmodium species and two negative (for the outer and nested PCR, respectively) were used in the genetic analysis [22].

To assess the specificity of the PCR analysis, four amplicons of $P$. vivax positive samples underwent sequencing reactions (Fig. 1) and they underwent to a further amplification of a region of the 18S rRNA gene different from the target region we used for the molecular detection [21]. Sequencing analyses were performed using an automated DNA sequencer (CEQ 8000, Beck$\left.\operatorname{man}^{\circledR}\right)$. Sequencing alignments were carried out using ClustalX [23].

\section{Genotyping of erythrocytes Duffy antigen by melting curve analysis}

To explore the possible susceptibility of the study population to $P$. vivax infection, the Duffy antigen genotype due to the SNP $-33 \mathrm{~T}>\mathrm{C}$ was investigated. Duffy genotype was analysed through the melting curve profile of a new-designed PCR method. The PCR amplified a fragment of 178 bp (from position 186-363, an. JN251917), encompassing the SNP in the GATA box (position 234). 


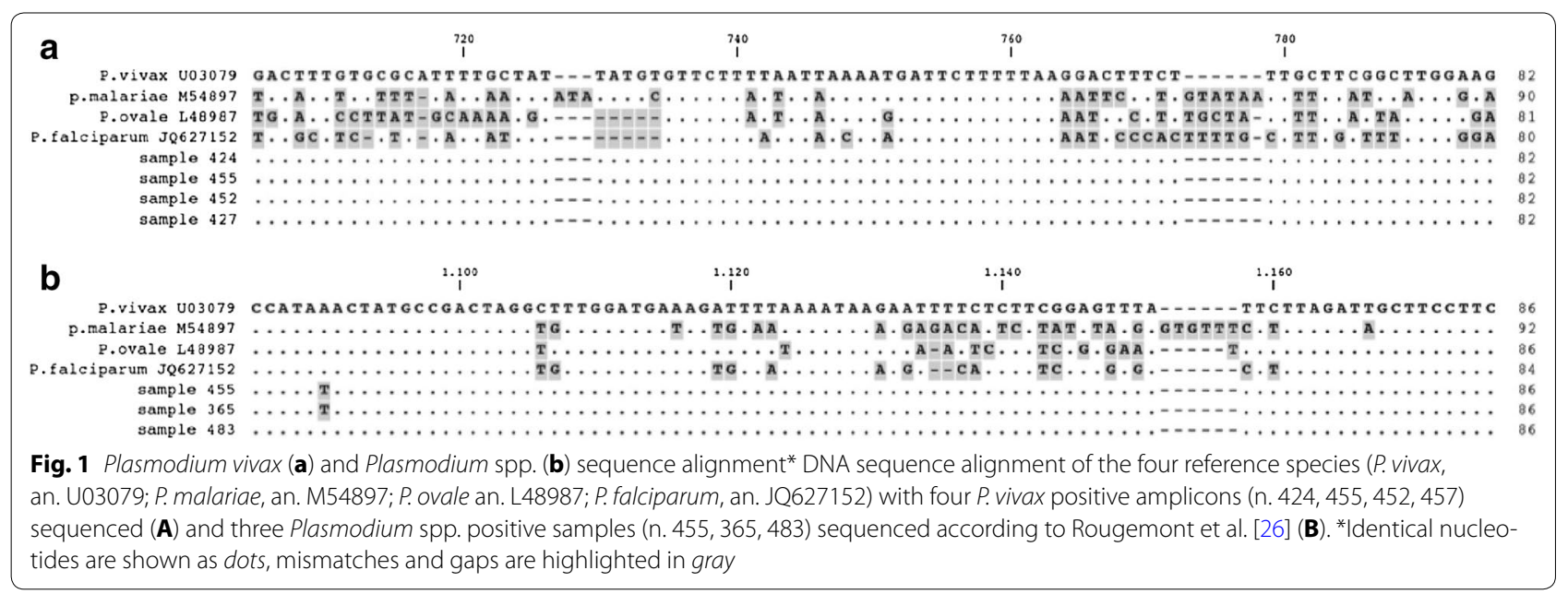

The sensor-probe was designed on the negative-phenotype. The PCR reaction was set-up in a final volume of $20 \mu \mathrm{l}$ using the XtraTaq pol system [24] with $0.3 \mu \mathrm{M}$ of forward (5'-CCTGTCCCTGCCCAGAA- $\left.3^{\prime}\right)$ and $0.5 \mu \mathrm{M}$ of reverse (5'-GGCATAGGGATAAGGGACT-3') primers, $0.2 \mu \mathrm{M}$ each of the anchor-probe $\left(5^{\prime} \mathrm{CY} 5\right.$ ACAGCCGTCCCAGCCC-3'PHO) and sensor probe (5'-TTACCTTGGAAGCACAGGCGC-3'FLU), $0.01 \%$ of BSA and $3 \mu \mathrm{l}$ of DNA. The reactions were performed on a Light Cycler or LC480 instruments (Roche Diagnostics, Switzerland). The amplification program consisted of $95{ }^{\circ} \mathrm{C}$ for $30 \mathrm{~s}$ and then 45 cycles of $95{ }^{\circ} \mathrm{C}$ for $10 \mathrm{~s}, 52^{\circ} \mathrm{C}$ for $30 \mathrm{~s}$ and $72{ }^{\circ} \mathrm{C}$ for $10 \mathrm{~s}$. The transition rates (TR) were $20{ }^{\circ} \mathrm{C} / \mathrm{s}$. The melting curve analysis consisted of $95{ }^{\circ} \mathrm{C}$ for $30 \mathrm{~s}, 55^{\circ} \mathrm{C}$ for $2 \mathrm{~min}$ with a TR of $20^{\circ} \mathrm{C} / \mathrm{s}$, and an acquisition step from 50 to $75{ }^{\circ} \mathrm{C}$ with a TR of $0.1{ }^{\circ} \mathrm{C} / \mathrm{s}$. The fluorescence signal was acquired using channel 670/530. A melting curve analysis was performed on two homozygous controls showing two different peak profiles at 60.5 and $64.5^{\circ} \mathrm{C}$ melting temperature, corresponding to -33TT (Caucasian, Duffy positive) and -33CC (Cameroonian, Duffy negative) genotypes, respectively (Fig. 2c). The positive controls were also sequenced (Fig. 2a, b).

\section{Statistical analysis}

Categorical variables (sex, provenance, ethnicity, pregnancy, comorbidities, previous anti-malarial self-medication) were reported as absolute number and percentage, and continuous data (age, days of diagnostic delay) were expressed as median and interquartile range. Chi square test (for categorical variables) and Mann-Whitney test (for continuous variables) were used to compare Plasmodium spp. positive $v s$ negative and $P$. falciparum positive vs $P$. vivax positive results. D'Agostino and Pearson omnibus normality test was applied to confirm the nonnormal distribution of quantitative parameters. Odds ratio (OR) with 95\% confidence interval (CI) were also calculated. The $\mathrm{R}$ (version 2.15.0, $\mathrm{R}$ foundation statistical Computing) and Prism (version 5.00.288, GraphPad Software, Inc) were employed as statistical software. Evaluation of Hardy-Weinberg equilibrium (HWE) was performed using the HWSIM software [25] and MonteCarlo permutation test performed when genotypic classes had an expected cell size of less than five.

\section{Results}

A total of 484 samples were consecutively collected from febrile outpatients. Population's characteristics are summarized in Table 1. Malaria parasite DNA was identified by nested-PCR in 70 samples (14.5\%): 68 cases of Plasmodium mono-infections (42 P. falciparum, 25 P. vivax, and $1 P$. malariae) and 2 cases of $P$. falciparum/P. vivax co-infections. Because of the unexpected frequency of $P$. vivax, in order to assess the specificity of the molecular analysis, four amplicons were purified, sequenced and aligned confirming the specificity of the analysis (Fig. 1a). Additionally, a subset of $P$. vivax positive samples by molecular analysis was analyzed by amplifying a different region of the rRNA $18 \mathrm{~S}$ gene [26]: three amplicons were sequenced and aligned confirming the $P$. vivax diagnosis (Fig. 1b). The proportion of $P$. falciparum and $P$. vivax infections was $9.1 \%(\mathrm{n}=44 / 484)$ and $5.6 \%(\mathrm{n}=27 / 484)$, respectively. Notably, 38.6\% $(\mathrm{n}=27 / 70)$ of Plasmodium positive PCR results were due to $P$. vivax infection. Male gender was associated with Plasmodium PCR positive result (OR 2.3; 95\% CI 1.39-3.89; $P=0.0014$ ) at univariate analysis (Table 1 ). No other correlation was found between PCR results (or Plasmodium species detected) and other demographic or clinical data collected (Table 1).

The Duffy antigen genotype (Fig. 2; Table 2) was assessed in a subset of 228 unrelated samples (27 P. vivax 


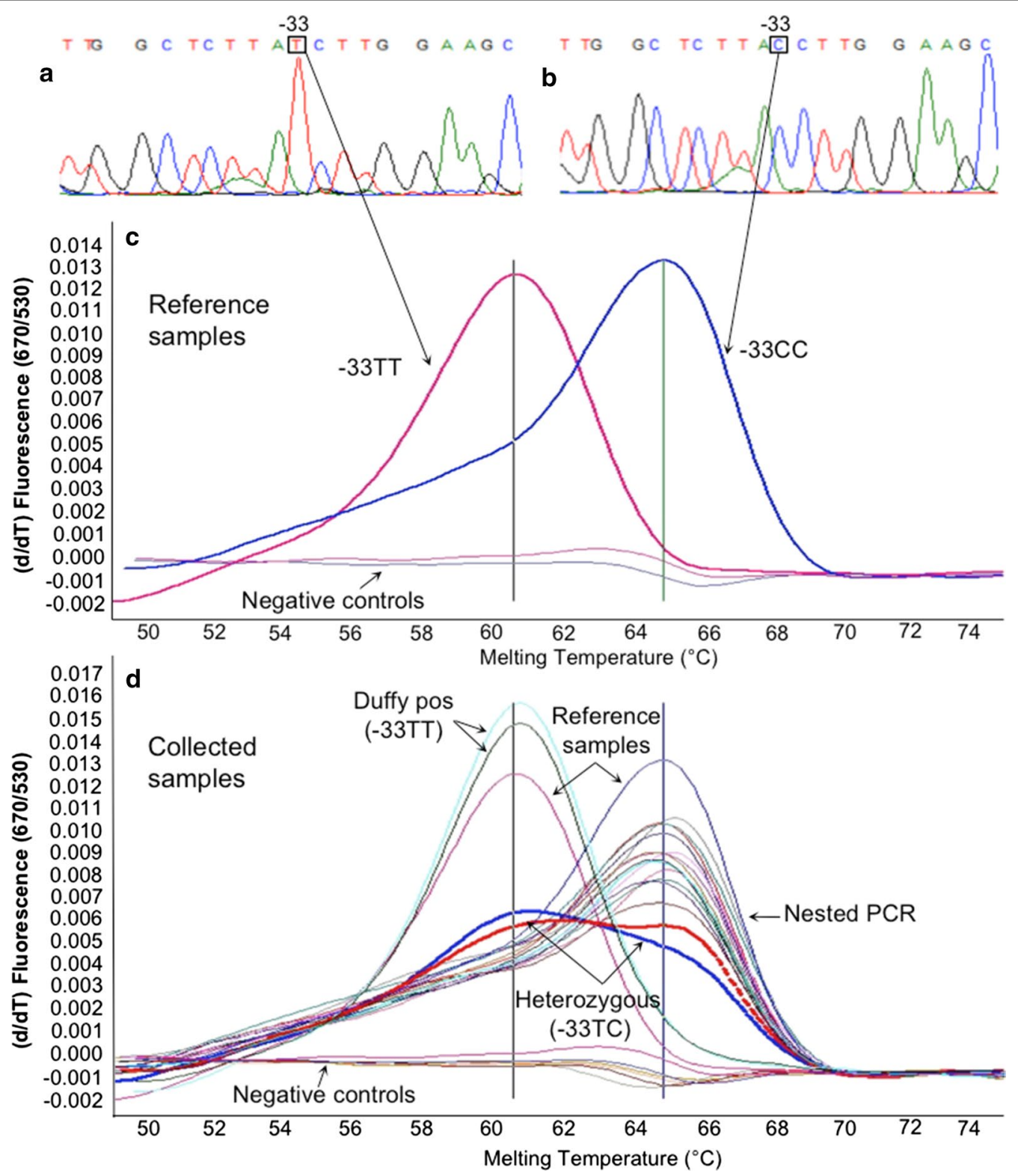

Fig. 2 Duffy antigen genotyping (SNP -33T>C in GATA box, DARC gene) by melting curve analysis. a Chromatogram of the Caucasian Duffy-positive phenotype (-33TT genotype), reference sample. b Chromatogram of the Cameroonian Duffy-negative phenotype (-33CC genotype), reference sample. c Melting curve analysis of the two reference samples: melting temperatures of 60.5 and $64.5^{\circ} \mathrm{C}$ for Duffy-positive (Caucasian) and Duffynegative (Cameroonian), respectively. $\mathbf{d}$ Melting curve analysis of a representative group of samples, including the two reference samples. Two heterozygous samples (thick red and blue lines) are also shown. Negative controls are in the lower part of the melting curves of $\mathbf{c}, \mathbf{d}$

positive and 201 randomly selected). Two Duffy-positive $(-33 \mathrm{TT})$, two heterozygous (-33TC), and 224 Duffynegative $(-33 \mathrm{CC})$ genotypes were detected. All $P$. vivax infected individuals showed a Duffy-negative genotype. Overall, the frequency of the $-33 \mathrm{~T}$ allele was $1.3 \%$, corresponding to a frequency of $1.7 \%(n=4 / 228)$ of Duffypositive phenotypes (homo- and heterozygotes). Then the HWE was tested. A lack of heterozygotes was assessed using Chi square analysis $\left(x^{2}=99.99,1 \mathrm{df}, P<0.001\right)$. The Monte-Carlo permutation test (10,000 iterations) gave a $P=0.0629$.

\section{Discussion}

The evidence of $P$. vivax infection in Duffy negative febrile individuals from the West Region of Cameroon is reported. The study population was mainly represented 
Table 1 Study population characteristics and comparison between Plasmodium spp. (P. spp.) PCR-pos vs PCR-neg groups, and between PCR-pos $P$. falciparum (Pf) vs $P$. vivax (Pv) patients (univariate analysis)

\begin{tabular}{|c|c|c|c|c|c|c|c|}
\hline Variable & Total population & $\begin{array}{l}\text { P. spp. PCR- } \\
(\mathrm{n}=414)\end{array}$ & $\begin{array}{l}\text { P. spp. PCR+ } \\
(\mathrm{n}=70)^{\mathrm{a}}\end{array}$ & $P$ value & $P f P C R+(n=42)^{b}$ & $P v$ PCR $+(\mathrm{n}=25)^{\mathrm{b}}$ & $P$ value \\
\hline \multicolumn{8}{|l|}{ Age (years), n (\%) } \\
\hline$\leq 5$ & $131(27.1 \%)$ & $112(27.1 \%)$ & $19(27.1 \%)$ & 0.153 & $11(26.2 \%)$ & $7(28.0 \%)$ & 0.906 \\
\hline $6-14$ & $31(6.4 \%)$ & $26(6.3 \%)$ & $5(7.1 \%)$ & & $2(4.8 \%)$ & $2(8 \%)$ & \\
\hline $15-24$ & $91(18.8 \%)$ & $78(18.8 \%)$ & $13(18.6 \%)$ & & $9(21.4 \%)$ & $4(16 \%)$ & \\
\hline $25-64$ & $198(40.9)$ & $171(41.3 \%)$ & $27(38.6 \%)$ & & $17(40.5 \%)$ & $9(36 \%)$ & \\
\hline$\geq 65$ & $33(6.8 \%)$ & $27(6.5 \%)$ & $6(8.6 \%)$ & & $3(7.1 \%)$ & $3(12 \%)$ & \\
\hline Median [IQR] & $24[4-40]$ & $23[4-43]$ & 24 [4-39] & 0.732 & $23[4-42]$ & $21[3-37]$ & 0.721 \\
\hline \multicolumn{8}{|l|}{ Sex, n (\%) } \\
\hline Male & $191(39.5 \%)$ & $151(36.5 \%)$ & $40(57.1 \%)$ & 0.001 & $24(57.1 \%)$ & $14(56 \%)$ & 1.000 \\
\hline Female & $293(60.5 \%)$ & $263(63.5 \%)$ & $30(42.9 \%)$ & & $18(42.9 \%)$ & $11(44 \%)$ & \\
\hline \multicolumn{8}{|l|}{ Provenance, n (\%) } \\
\hline Urban & $316(65.3 \%)$ & $264(63.8 \%)$ & $52(74.3 \%)$ & 0.103 & $30(71.4 \%)$ & $19(76 \%)$ & 0.780 \\
\hline Rural & $168(34.7 \%)$ & $150(36.2 \%)$ & $18(25.7 \%)$ & & $12(28.6 \%)$ & $6(24 \%)$ & \\
\hline \multicolumn{8}{|l|}{ Ethnicity, n (\%) } \\
\hline Bamiléké & 429 (89\%) & $363(88 \%)$ & $66(94 \%)$ & 0.151 & $40(95 \%)$ & $24(96 \%)$ & 1.000 \\
\hline Others & $55(11 \%)$ & $51(12 \%)$ & $4(6 \%)$ & & $2(5 \%)$ & $1(4 \%)$ & \\
\hline \multicolumn{8}{|l|}{ Co-morbidity, n (\%) } \\
\hline No & $448(92.6 \%)$ & $383(92.5 \%)$ & 65 (92.9\%) & 1.000 & 38 (90.5\%) & $24(96 \%)$ & 0.643 \\
\hline Yes & $36(7.4 \%)$ & $31(7.5 \%)$ & $5(7.1 \%)$ & & $4(9.5 \%)$ & $1(4)$ & \\
\hline Diabetes & $8(1.6 \%)$ & $8(1.9 \%)$ & $0(0 \%)$ & & $0(0 \%)$ & $0(0 \%)$ & \\
\hline $\mathrm{AHT}$ & $19(3.9 \%)$ & $15(3.7 \%)$ & $4(5.7 \%)$ & & $3(7.1 \%)$ & $1(4 \%)$ & \\
\hline AHT + diabetes & $5(1.1 \%)$ & $5(1.2 \%)$ & $0(0 \%)$ & & $0(0 \%)$ & $0(0 \%)$ & \\
\hline $\begin{array}{l}\mathrm{AHT}+\text { bronchial } \\
\text { asthma }\end{array}$ & $1(0.2 \%)$ & $1(0.2 \%)$ & $0(0 \%)$ & & $0(0 \%)$ & $0(0 \%)$ & \\
\hline Bronchial asthma & $1(0.2 \%)$ & $1(0.2 \%)$ & $0(0 \%)$ & & $0(0 \%)$ & $0(0 \%)$ & \\
\hline HIV infection & $1(0.2 \%)$ & $1(0.2 \%)$ & $0(0 \%)$ & & $0(0 \%)$ & $0(0 \%)$ & \\
\hline HCV infection & $1(0.2 \%)$ & $0(0 \%)$ & $1(1.4 \%)$ & & $1(2.4 \%)$ & $0(0 \%)$ & \\
\hline \multicolumn{8}{|l|}{ Pregnancy, $n(\%)^{c}$} \\
\hline Yes & $17(5.8 \%)$ & $15(5.7 \%)$ & $2(6.7 \%)$ & 0.688 & $0(0 \%)$ & $2(18.2 \%)$ & 0.135 \\
\hline No & $276(94.2 \%)$ & $248(94.3 \%)$ & $28(93.3 \%)$ & & $18(100 \%)$ & $9(81.8 \%)$ & \\
\hline \multicolumn{8}{|c|}{ Previous anti-malarial self-medication, $\mathrm{n}(\%)^{\mathrm{d}}$} \\
\hline Yes & $198(40.9 \%)$ & $168(40.6 \%)$ & $30(42.9 \%)$ & 0.952 & $18(42.9 \%)$ & $11(44 \%)$ & 0.952 \\
\hline No & $286(59.1 \%)$ & $246(59.4 \%)$ & $40(57.1 \%)$ & & $24(57.1 \%)$ & $14(56 \%)$ & \\
\hline \multicolumn{8}{|c|}{ Diagnostic delay (days) } \\
\hline Median [range] & $3[2-7]$ & $3[1-6]$ & $3[2-7]$ & 0.144 & $3.5[2-7]$ & $3[2-7]$ & 0.707 \\
\hline
\end{tabular}

by young individuals (median age 24 years), and in particular children. Notably, the only factor associated with a higher frequency of malaria infection was male gender (see Table 1): a possible explanation of this statistically significant difference could be that male patients seek for medical advice only in more severe cases, or due to chance alone.
Historically, $P$. vivax infection has been considered as "benign" malaria, and the Duffy-negative phenotype as full protective against $P$. vivax infection. But, recently, both axioms have been questioned. In fact, there are several reports of severe vivax malaria $[4,8,9]$ as well as of $P$. vivax infection among Duffy-negative individuals from Angola [27], Cameroon [16-18], Equatorial Guinea [27], 
Table 2 Duffy-antigen genotyping results $(n=228)$

\begin{tabular}{lllr}
\hline PCR-analysis results & \multicolumn{2}{l}{$\begin{array}{l}\text { Duffy-antigen genotyp- } \\
\text { ing }\end{array}$} \\
\cline { 2 - 4 } & -33TT & -33TC & -33CC \\
\hline P. falciparum positive & 0 & 0 & 11 \\
P. malariae positive & 0 & 0 & 1 \\
P. vivax positive & 0 & 0 & 25 \\
P. falciparum/P. vivax positive (co-infection) & 0 & 0 & 2 \\
Plasmodium negative & 2 & 2 & 185 \\
Total & 2 & 2 & 224 \\
\hline
\end{tabular}

Ethiopia [28, 29], Kenya [30], Madagascar [13], Mauritania [31] and Brazil [32, 33]. Three recent studies showed the circulation of $P$. vivax in the southern part of Cameroon (Table 3; Fig. 3) [16-18]. In comparison with these studies [16-18] data from the West region of Cameroon confirm the circulation of $P$. vivax in native individuals with Duffy-negative genotype (Fig. 3), and showed a higher relative proportion of $P$. vivax infection, possibly linked to the higher altitude of the study area. Moreover, considering that the study was conducted when the anopheline density was at its lowest (main dry season) [19], these data possibly underestimate the real circulation of $P$. vivax in West-Cameroon, where climatic conditions during the two rainy seasons may facilitate its circulation $[2,3]$.

The Cameroonian population, as well as other West and Central African populations (and their descendants), show a 95-99\% frequency of Duffy-negative phenotype [14], possibly as a consequence of the positive selective process linked to an ancient (100,000 years) presence of P. vivax in sub-Saharan Africa [3]. In this study, the HWE assessment on the Duffy genotype distribution showed a lack of heterozygotes (using Chi square analysis), and the Monte-Carlo permutation test being on the verge of significance. It is noteworthy that the slight departure from the HWE of genotype frequencies for Duffy is probably due to the effect of natural selection exerted by $P$. vivax (one of the theoretical assumptions for HWE is absence of natural selection), similar to that seen in Madagascar [34]. It is also worth considering the possible deviation from HWE with respect to the biased sampling of febrile individuals.

According to some authors, the maintenance of $P$. vivax circulation in Duffy-negative population context is possibly related to the presence of reservoirs of Duffy-positive individuals $(1-5 \%)$ presumably present in the local population [5] or, in restricted areas, to $P$. vivax and/or $P$. vivax-like infections found in apes [35]. Moreover, $P$. vivax circulation might be facilitated by the highly specific vectorial competence showed by the Anopheles gambiae and Anopheles funestus complexes that circulate in Africa [30, 36]. In this study, the measure Duffy antigen expression on erythrocytes at the protein level was not assessed; however, the Duffy genotype predicts its phenotype with high consistency [13]. In the population study, the $-33 \mathrm{~T}$ allele frequency was $1.3 \%$, confirming a minimal presence of Duffy-positive individuals also within the Bamiléké ethnic group in West Cameroon. Moreover, the country (mainly in the southern part) accounts for a significant population of great apes; a recent study has showed a relevant $2.3 \%(\mathrm{n}=45 / 2168)$ of $P$. vivaxlike infection among great apes living in Cameroon [37]. These elements, together with the climate and geographic variety of Cameroon, suggest that $P$. vivax circulates in different areas of the country. Some investigators suggest that $P$. vivax may be in the process to evolving the ability to infect Duffy-negative erythrocytes $[13,15]$, possibly involving parasite DBPs and/or reticulocyte binding proteins $[38,39]$. The alternative yet-uncharacterized Duffyindependent erythrocyte invasion pathway is likely to be less efficient [13], leading to lower level of parasitaemia as observed in carriers of heterozygous Duffy-genotype

Table 3 Vivax malaria in Cameroon

\begin{tabular}{|c|c|c|c|c|c|c|}
\hline \multirow[t]{2}{*}{ Study (ref.) } & \multirow[t]{2}{*}{ Study site } & \multirow[t]{2}{*}{ Total population, $\mathbf{n}$} & \multirow[t]{2}{*}{ Malaria cases, n (\%) } & \multicolumn{3}{|c|}{ Vivax malaria cases } \\
\hline & & & & $\mathbf{n}$ & $\%^{a}$ & Duffy neg, n \\
\hline [16] & Five sites $^{b}$ & $485^{c}$ & $201(41.4)$ & 8 & 4 & $8 / 8$ \\
\hline$[17]$ & Douala city & $60^{c}$ & $43(71.7)$ & 10 & 23.2 & $10 / 10$ \\
\hline [18] & Bolifamba village ${ }^{d}$ & $269^{e}$ & $87(32.3)$ & 13 & 4.8 & $6 / 13$ \\
\hline Present study & Dschang $^{\mathrm{f}}$ & $484^{c}$ & $70(14.5)$ & 27 & 38.6 & $27 / 27$ \\
\hline
\end{tabular}

a Relative proportion of $P$. vivax infection among total malaria cases

b Five sites in southern Cameroon (Littoral, South, Centre and East regions)

c All symptomatic (febrile) individuals

d South-West region of Cameroon

e All asymptomatic individuals

${ }^{f}$ West region of Cameroon 


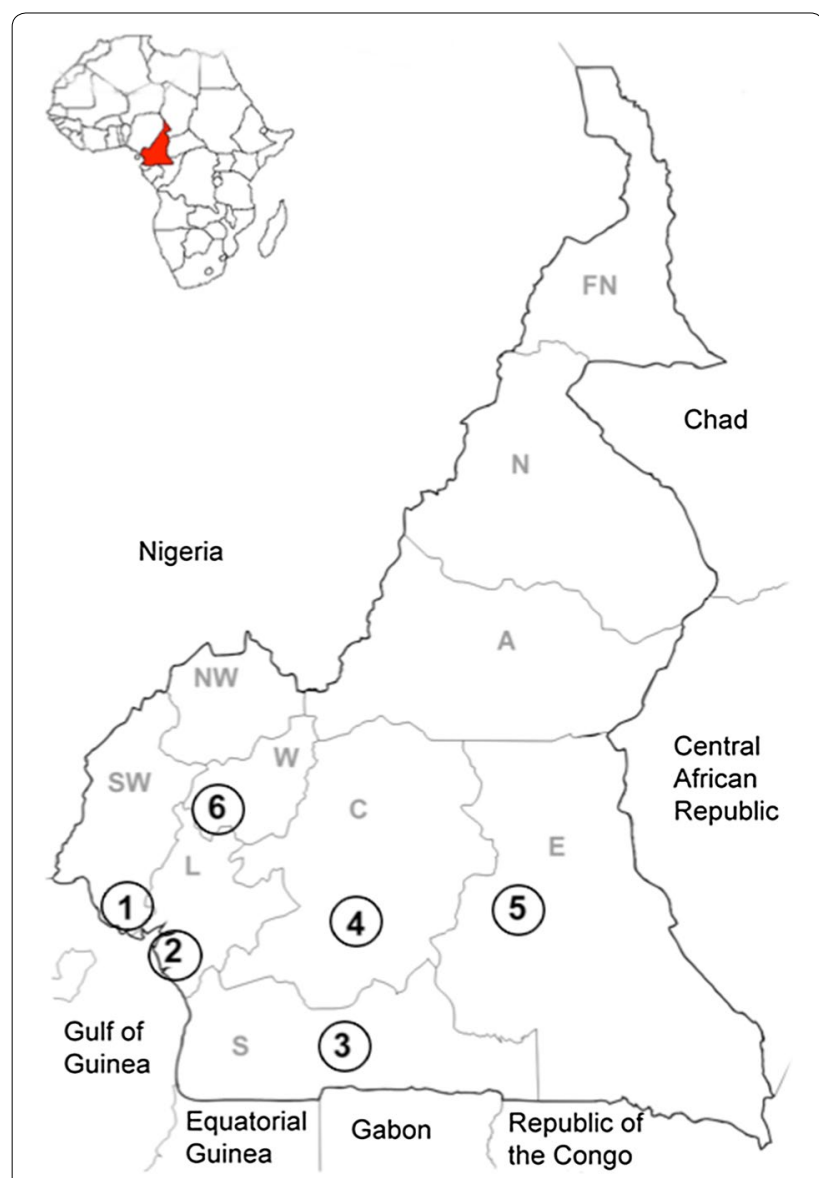

Fig. 3 Plasmodium vivax infection in Cameroon. Cameroonian regions: FN Far North, N North, A Adamaoua, NW North-West, SW South-West, WWest, L Littoral, C Centre, S South, E East. Study sites: 1 Bolifamba village (South-West Region): 13/269 (4.8\%) P. vivax infections [18]; 2 Douala (Littoral Region): 2/52 (3.8\%) [16] and 6/60 (10\%) [17] P. vivax infections; 3 Ebolowa (South Region): 3/60 (5\%) P. vivax infections [16]; 4 Yaoundé (Centre Region): 1/29 (3.4\%) P. vivax infection [16]; 5 Bertoua (East region): 2/25 (8\%) P. vivax infections [16]; 6 Dschang (West Region): 27/484 (5.6\%) P. vivax infections (present study)

(-33TC) from Papa New Guinea [40]. Thus, the reason underlying the reported $P$. vivax infection in Duffy-negative individuals from context with very low presence of Duffy-positive phenotypes, as in the present study, remains unclear. All these elements underline the basic knowledge gaps of $P$. vivax life cycle [7-9] and the need to assess the real circulation of $P$. vivax in sub-Saharan Africa [41] also in the broader perspective of malaria eradication worldwide.

Although $P$. vivax is susceptible to several anti-malarial drugs (i.e. chloroquine, quinine, artemisinin and its derivatives), primaquine (PQ) is the only licensed drug active against the hypnozoites to prevent $P$. vivax relapses from the liver [6]. Moreover, a true resistance to PQ in $P$. vivax hypnozoites has not been described, suggesting a role for host factors in drug failure [42]. Primaquine is metabolized in the liver by the enzyme cytochrome P450-2D6 (CYP2D6), possibly leading to a metabolite responsible for hypnozoite killing [42]. Thus, defective CYP2D6 metabolism could be associated with PQ failure [43]. Furthermore, the risk of acute haemolytic anaemia in carriers of glucose-6-phosphate dehydrogenase (G6PD) deficiency is a safety concern for PQ use (14 days at $0.5 \mathrm{mg} / \mathrm{kg}$ ), and data on African G6PD deficiency are not exhaustive [44]. Available data related to G6PD in Cameroon are scarce, with one published survey reporting the G6PD deficiency prevalence being 6.6\% [45]. Thus, considering the observed $P$. vivax circulation in different regions of Cameroon, larger studies assessing G6PD deficiency prevalence and CYP2D6 polymorphism frequency in the whole country are necessary in order to ensure a safer therapeutic use of PQ.

The present study has some limitations. Data on parasitaemia of Plasmodium species infections are lacking because the diagnosis was based only on a molecular qualitative technique and because of the lack of experienced local microscopists. Moreover, although $40 \%$ of the participants reported anti-malarial self-medication before the medical consultation, data on drugs, dosage and duration were not reported, as well as follow-up data of infected cases.

\section{Conclusion}

The present study reports the molecular evidence of $P$. vivax circulation in the West region of Cameroon among symptomatic Duffy-negative outpatients, perhaps with the highest proportion of $P$. vivax infection when compared to previous studies in the country [16-18]. These results suggest the need for assessing the real circulation of $P$. vivax in West/Central African countries to plan public health activities in order to improve the local microscopic diagnostic capacity, and to ensure a more effective and safer therapeutic management of vivax malaria attacks and relapses.

\section{Authors' contributions}

GRu: Conception and design of the study, data collection and interpretation, drafting the manuscript. GF: Conception of the study, molecular analysis, data interpretation, drafting the manuscript. GMP: Design of the study, data interpretation, drafting the manuscript. GBDD: Data collection and interpretation, drafting the manuscript. AP, RDeS: Molecular analysis, data interpretation. GT: Data interpretation, statistical analysis, drafting the manuscript. MM, MSS: Design of the study, data interpretation. W: Conception of the study, data interpretation, revision of the manuscript; GRe, FRL: Design of the study, data interpretation, revision of the manuscript. All authors read and approved the final manuscript.

\section{Author details}

${ }^{1}$ Department of Public Health and Infectious Diseases, Sapienza University of Rome, Piazzale Aldo Moro, 00185 Rome, Italy. ${ }^{2}$ Department of Molecular Biology, Immunology and Experimental Medicine, Army Medical and Veterinary Research Centre, Via di Santo Stefano Rotondo, 00184 Rome, Italy. ${ }^{3}$ BUP Core Laboratory, Botswana-University of Pennsylvania Partnership (BUP), P O 
Box AC 157 ACH, Gaborone, Botswana. ${ }^{4}$ Department of Biomedical Sciences, University of Dschang, BP 96 Dschang, Cameroon. ${ }^{5}$ Department of Infectious, Parasitic and Immune-mediated Diseases, Istituto Superiore di Sanità, Viale Regina Elena, 299, 00161 Rome, Italy.

\section{Acknowledgements}

We would like to thank Dr. Andrea Bosman (WHO, Geneva) for his critical review of the paper.

\section{Competing interests}

The authors declare that they have no competing interests.

\section{Availability of data and materials}

All data generated or analysed during this study are included in this article.

\section{Ethics approval and consent to participate}

This study was conducted in accordance with the guidelines of the Helsinki Declaration of the year 2000, with the approval of the "Cameroon Bioethics Initiative" (CAMBIN) (Ref. CBI/249/ERCC/CAMBIN). Signed informed consent for multiple genetic and epidemiological analyses was obtained from all adults and from all children's parents/caregivers.

\section{Funding}

No specific financial support has been received to realize this work. The work has been performed with internal ordinary funds from Sapienza University of Rome.

Received: 7 October 2016 Accepted: 6 February 2017

Published online: 14 February 2017

\section{References}

1. WHO. World malaria report, 2015. Geneva: World Health Organization; 2015. http://www.who.int/malaria/publications/world-malariareport-2015/report/en/. Accessed 1 Aug 2015.

2. Price RN, Tjitra E, Guerra CA, Yeung S, White NJ, Anstey NM. Vivax malaria: neglected and not benign. Am J Trop Med Hyg. 2007;77(Suppl 6):79-87.

3. Culleton RL, Carter R. African Plasmodium vivax: distribution and origins. Int J Parasitol. 2012:42:1091-7.

4. Baird JK. Neglect of Plasmodium vivax malaria. Trends Parasitol. 2007;23:533-9.

5. Culleton RL, Ndounga M, Zeyrek F, Coban C, Casimiro P, Takeo S, et al. Evidence for the transmission of Plasmodium vivax in the Republic of the Congo, West Central Africa. J Infect Dis. 2009;200:1465-9.

6. White NJ. Determinants of relapse periodicity in Plasmodium vivax malaria. Malar J. 2011;10:297.

7. Anstey NM, Russell B, Yeo TW, Price RN. The pathophysiology of vivax malaria. Trends Parasitol. 2009;25:220-7.

8. Mueller I, Galinski MR, Baird JK, Carlton JM, Kochar DK, Alonso PL, et al. Key gaps in the knowledge of Plasmodium vivax, a neglected human malaria parasite. Lancet Infect Dis. 2009;9:555-66.

9. Anstey NM, Douglas NM, Poespoprodjo JR, Price RN. Plasmodium vivax: clinical spectrum, risk factors and pathogenesis. Adv Parasitol. 2012:80:151-201.

10. Miller LH, Mason SJ, Clyde DF, McGinniss MH. The resistance factor to Plasmodium vivax in blacks. The Duffy-blood-group genotype, FyFy. N Engl J Med. 1976;295:302-4.

11. Chaudhuri A, Nielsen S, Elkjaer ML, Zbrzezna V, Fang F, Pogo AO Detection of Duffy antigen in the plasma membranes and caveolae of vascular endothelial and epithelial cells of nonerythroid organs. Blood. 1997;89:701-12

12. Zimmerman PA, Ferreira MU, Howes RE, Mercereau-Puijalon O. Red blood cell polymorphism and susceptibility to Plasmodium vivax. Adv Parasitol. 2013;81:27-76.

13. Ménard D, Barnadas C, Bouchier C, Henry-Halldin C, Gray LR, Ratsimbasoa A, et al. Plasmodium vivax clinical malaria is commonly observed in Duffynegative Malagasy people. Proc Natl Acad Sci USA. 2010;107:5967-71.

14. Howes RE, Patil AP, Piell FB, Nyangiri OA, Kabaria CW, Gething PW, et al. The global distribution of the Duffy blood group. Nat Commun. 2011;2:266.
15. Rosenberg R. Plasmodium vivax in Africa: hidden in plain sight? Trends Parasitol. 2007;23:193-6.

16. Ngassa Mbenda HG, Das A. Molecular evidence of Plasmodium vivax mono and mixed malaria parasite infections in Duffy-negative native Cameroonians. PLoS ONE. 2014;9:e103262.

17. Ngassa Mbenda HG, Gouado I, Das A. An additional observation of Plasmodium vivax malaria infection in Duffy- negative individuals from Cameroon. J Infect Dev Ctries. 2016;10:682-6.

18. Fru-Cho J, Bumah W, Safeukui I, Nkuo-Akenji T, Titanji PKV, Haldar K. Molecular typing reveals substantial Plasmodium vivax infection in asymptomatic adults in a rural area of Cameroon. Malar J. 2014:13:170.

19. Tchuinkam T, Simard F, Lélé-Defo E, Téné-Fossog B, Tateng-Ngouateu A, Antonio-Nkondjio C, et al. Bionomics of Anopheline species and malaria transmission dynamics along an altitudinal transect in Western Cameroon. BMC Infect Dis. 2010;10:119.

20. Faggioni G, Borgiani P, Bottini N, Gloria-Bottini F, Tontoli F, Contreas V, et al. Identification of two SNPs in the $5^{\prime}$ flanking region of the ACP1 gene and evaluation of disequilibrium among polymorphic sites. Ann Hum Genet. 2002;66:245-54.

21. Snounou G, Viriyakosol S, Zhu XP, Jarra W, Pinheiro L, do Rosario VE, et al. High sensitivity of detection of human malaria parasites by the use of nested polymerase chain reaction. Mol Biochem Parasitol. 1993;61:315-20.

22. ATCC (American Type Culture Collection), Manassas, Virginia, USA. www. atcc.org. Accessed 5 Sept 2016.

23. SFI-UCD (Science Foundation Ireland-University College Dublin). Cluster $\mathrm{X}$-Multiple alignment of nucleic acid and protein sequences. www. clustal.org. Accessed 5 Sept 2016.

24. GeneSpin S.r.l. www.genespin.com. Accessed 5 Sept 2016.

25. HWSIM Software. http://krunch.med.yale.edu/hwsim/. Accessed 5 Sept 2016.

26. Rougemont M, Van Saanen M, Sahli R, Hinrikson HP, Bille J, Jaton K. Detection of four Plasmodium species in blood from humans by $18 \mathrm{~S}$ rRNA gene subunit-based and species-specific real-time PCR assays. J Clin Microbiol. 2004:42:5636-43.

27. Mendes C, Dias F, Figueiredo J, Mora VG, Cano J, de Sousa B, et al. Duffy negative antigen is no longer a barrier to Plasmodium vivax - molecular evidences from the African West Coast (Angola and Equatorial Guinea). PLoS Negl Trop Dis. 2011;5:e1192.

28. Woldearegai TG, Kremsner PG, Kun JF, Mordmüller B. Plasmodium vivax malaria in Duffy-negative individuals from Ethiopia. Trans R Soc Trop Med Hyg. 2013;107:328-31.

29. Lo E, Yewhalaw D, Zhong D, Zemene E, Degefa T, Tushune K, et al. Molecular epidemiology of Plasmodium vivax and Plasmodium falciparum malaria among Duffy-positive and Duffy-negative populations in Ethiopia. Malar J. 2015:14:84.

30. Ryan JR, Stoute JA, Amon J, Dunton RF, Mtalib R, Koros J, et al. Evidence for transmission of Plasmodium vivax among a Duffy antigen negative population in Western Kenya. Am J Trop Med Hyg. 2006;75:575-81.

31. Wurtz N, Lekweiry KM, Bogreau H, Pradines B, Rogier C, Boukhary AO, et al. Vivax malaria in Mauritania includes infection of a Duffy-negative individual. Malar J. 2011;10:336.

32. Cavasini CE, Mattos LC, Couto AA, Bonini-Domingos CR, Valencia SH, Neiras WC, et al. Plasmodium vivax infection among Duffy antigen-negative individuals from the Brazilian Amazon region: an exception? Trans R Soc Trop Med Hyg. 2007;101:1042-4.

33. Carvalho TA, Queiroz M, Cardoso G, Diniz I, Silva AN, Pinto AY, et al. Plasmodium vivax infection in Anajas, State of Para: no differential resistance profile among Duffy-negative and Duffy-positive individuals. Malar J. 2012;11:430.

34. Hodgson JA, Pickrell JK, Pearson LN, Quillen EE, Prista A, Rocha J, et al. Natural selection for the Duffy-null allele in the recently admixed people of Madagascar. Proc Biol Sci. 2014;281:20140930.

35. Culleton RL, Ferreira PE. Duffy phenotype and Plasmodium vivax infections in humans and apes, Africa. Emerg Infect Dis. 2012;18:1704-5.

36. Taye A, Hadis M, Adugna N, Tilahun D, Wirtz RA. Biting behavior and Plasmodium infection rates of Anopheles arabiensis from Sille, Ethiopia. Acta Trop. 2006;97:50-4.

37. Liu W, Li Y, Shaw KS, Learn GH, Plenderleith $\sqcup$, Malenke JA, et al. African origin of the malaria parasite Plasmodium vivax. Nat Commun. 2014;5:3346. 
38. Galinski MR, Medina CC, Ingravallo P, Barnwell JW. A reticulocyte-binding protein complex of Plasmodium vivax merozoites. Cell. 1992;69:1213-26.

39. Carlton JM, Adams JH, Silva JC, Bidwell SL, Lorenzi H, Caler E, et al. Comparative genomics of the neglected human malaria parasite Plasmodium vivax. Nature. 2008;455:757-63.

40. Kasehagen LJ, Mueller I, Kiniboro B, Bockarie MJ, Reeder JC, Kazura JW, et al. Reduced Plasmodium vivax erythrocyte infection in PNG Duffynegative heterozygotes. PLoS ONE. 2007;2:e336.

41. Howes RE, Reiner RC Jr, Battle KE, Longbottom J, Mappin B, Ordanovich $D$, et al. Plasmodium vivax transmission in Africa. PLoS Negl Trop Dis. 2015:9:e0004222.
42. Baird JK, Hoffman SL. Primaquine therapy for malaria. Clin Infect Dis. 2004;39:1336-45.

43. Bennett JW, Pybus BS, Yadava A, Tosh D, Sousa JC, McCarthy WF, et al. Primaquine failure and cytochrome P-450 2D6 in Plasmodium vivax malaria. N Engl J Med. 2013;369:1381-2

44. Howes RE, Dewi M, Piel FB, Monteiro WM, Battle KE, Messina JP, et al. Spatial distribution of G6PD deficiency variants across malaria-endemic regions. Malar J. 2013;12:418.

45. Bernstein SC, Bowman JE, Kaptue Noche L. Population studies in Cameroon: hemoglobin S, glucose-6-phosphate dehydrogenase deficiency and falciparum malaria. Hum Hered. 1980;30:251-8.

\section{Submit your next manuscript to BioMed Central and we will help you at every step:}

- We accept pre-submission inquiries

- Our selector tool helps you to find the most relevant journal

- We provide round the clock customer support

- Convenient online submission

- Thorough peer review

- Inclusion in PubMed and all major indexing services

- Maximum visibility for your research

Submit your manuscript at

www.biomedcentral com/submit 